East African Medical Journal Vol. 77 No. 11 November 2000

FREE CONJUNCTIVAL AUTOGRAFT IN THE MANAGEMENT OF ADVANCED PRIMARY AND RECURRENT PTERYGIA

A. Seid, MD, Resident and A. Bejiga, MD, Certificate in Ophthalmology, Diploma in Clinical Epidemology and Biostatistics. Department of Ophthalmology, Faculty

of Medicine, Menelik II Hospital Addis Ababa University, Addis Ababa, Ethiopia.

Request for reprints to: Dr. A. Seid, P. O. Box 12039, Addis Ababa, Ethiopia.

\title{
FREE CONJUNCTIVAL AUTOGRAFT IN THE MANAGEMENT OF ADVANCED PRIMARY AND RECURRENT PTERYGIA
}

\author{
A. SEID and A. BEJIGA
}

\begin{abstract}
Objectives: To evaluate the outcome of free conjuctival autograft in patients with grades III and IV pterygia and to determine the post-operative recurrence rate.

Design: A prospective descriptive study.

Setting: Menelik II Hospital, Addis Ababa, Ethiopia.

Participants: Thirty four patients, 32 with primary and two with recurrent pterygia.

Intervention: A superficial Keratectomy extending beyond the corneal lesion all around and sufficiently deep to Bowman's layer to produce a perfectly clear cornea in the excised area followed by suture a free conjuctival autograft on the excised area.

Main outcome measures: Improvement in visual acuity and recurrence rate of pterygia at follow up.

Results: Of the 32 patients followed up, the visual acuity remained the same on eight and improved in $\mathbf{2 4}$ cases. There were no intraoperative complications. Pterygia recurred in two patients between three and four months postoperatively.

Conclusion: This study suggests that a free conjuctival autograft in the management of stage III and IV pterygia is a useful operation resulting in a very low recurrence rate of the pathology.
\end{abstract}

\section{INTRODUCTION}

Pterygium is a triangular sheet of fibrovascular tissue, which invades the cornea(1-4). It occurs in the interpalpebral fissure, more common on the nasal side of the eye and often bilateral(1,2,5). Physicians have known pterygia for thousands of years(2,6-8). Despite being recognised for many years and being very common in some parts of the world, very little is known about its pathogenesis. This ignorance is reflected in the poor results of intervention and the wide range of treatments advocated(6,7).

Current theories concerning the aetiology and the pathogenesis of pterygium include ultraviolet light (UVL) exposure $(2,7,9)$, infrared light exposure(7), chronic inflammation, elastodysplasia and elastodystrophy and stem cell aplasia(10). Cameron's global survey of pterygium established a direct relationship between prevalence rates and proximity to the equator $(2,7)$. For example, locations at $12^{\circ}$ of latitude have prevalence rates as high as $22.5 \%$, compared with $2 \%$ at locations above the fortieth parallel(7).

The presence of unsightly and uncomfortable lump on the surface of the eye as well as visual loss is usually indication enough for surgical removal(6). Unfortunately, excision is often complicated by recurrence which is usually more troublesome than their antecedents $(11,12)$ and also tends to be more aggressive in its growth pattern than the original tissue. There have been numerous procedures suggested for the treatment of primary and secondary pterygia. These extend from simple pterygium excision to free conjunctival autograft after surgical excision(1,3-5,11,13,14).

Recurrence was defined differently by different study groups. Some define recurrence as post-operative regrowth of fibrovascular tissue similar to the original pterygium; and others consider recurrence if post-operative regrowth of fibrovascular tissue crosses the limbus $(4,13)$. Rates of recurrence in primary pterygia treated by simple surgical excision ranges from $32 \%-89 \%(3,4,14,15)$. Adjunctive treatments (after surgical excision) have been introduced to reduce the rate of recurrence, but different adverse effects have accompanied them. Mitomycin C (0.04\%) causes scleral ulceration, uveitis, secondary glaucoma, corneal edema or perforation and cataract(4). Beta irradiation might result in mild discomfort, decreased visual acuity, endophthalmitis, symblepharon, corneal and scleral ulceration $(4,9)$ Although low dose mitomycin $\mathrm{C}(0.02 \%)$ was found to be effective for both primary and recurrent pterygia dropping the recurrence rate to $3 \%$ and $5 \%$, respectively $(13,16,17)$, it is difficult to handle, as it needs refrigeration.

In the last quarter of the twentieth century, free conjunctival autografting has been advocated as an effective 
method of reducing recurrence rates for both primary and recurrent pterygia to $2-35 \%(3,4,12,15)$. The outcome of conjunctival autografting has never been evaluated among Ethiopian patients. Therefore the purpose of this study was to assess the outcome of free conjunctival autografting technique in the Ethiopian settings.

\section{MATERIALS AND METHODS}

From June 1996 to May 1997, all cases of primary and recurrent pterygia requiring surgery were collected at Menelik II Hospital. Primary pterygium is defined as a degenerative and hyperplastic process in which there is encrochment of the bulbar conjunctiva on the cornea. Secondary pterygium is defined as the presence of both fibrous and vascular encroachment across the limbus and follows operation for primary or secondary pterygium $(3,4)$.

In our study recurrence was defined as re-growth of fibrovascular tissue which crosses the limbus into the clear cornea. Pterygium was graded according to its size involving the clear cornea as follows:

\section{G-I : If the pterygium covers less than $1.5 \mathrm{~mm}$}

G-II : Less than half radius of the cornea.

G-III : Over half radius of the cornea.

G-IV : Pupillary margin and beyond.

Patients labelled as grades III and IV were considered as candidates for free conjunctival autograft after pterygium excision. Informed consent was obtained from each patient. Those patients who agreed to be operated on were included in the study. All the necessary data such as age, sex, address, previous surgery, medical treatment, profession, duration of pterygium were collected and recorded in a prepared format.

Indications for surgery were irritation (itching, tearing, foreign body sensation) or visual reduction attributed to pterygium as well as cosmetic demand. Only cases with nasal pterygia were included in the study. Those patients with previous ocular surgery other than pterygium, ocular trauma, symblepharon, pseudopterygium and pus pouring chronic dacryocytitis were excluded from the study. Those patients who fulfilled the criteria were subjected to pterygium excision with free conjunctival autograft.

The operation procedure was as follows. Topical $0.5 \%$ tetracaine drop was instilled, and lids cleaned with $70 \%$ alcohol. Retrobulbar and lidblock with $2 \%$ lidocaine anaesthetic with adrenaline was given. Lids were again cleaned with $70 \%$ alcohol and irrigated with normal saline and draped. Lid speculum was applied to expose the operation area. Traction sutures were applied at 6 and 12 o'clock position of the limbus with 5/o silk. Then the circumference of pterygium at the limbus and its radial scleral extension was measured with Castroveijo calliper and marked by needle 3 puncture. Later on the head of pterygium was grasped with fine toothed forceps near the apex and put on tension by drawing it away from the cornea. This manoeuvre made it easy to achieve a superficial keratectomy extending a little beyond the corneal lesion all around and sufficiently deep to Bowman's layer to produce a perfectly clear cornea in the excised area.

The keratectomy was carried out to the limbus with Bard Parker No. 15 surgical blade. Thereafter the involved conjunctiva with underlying Tendon's capsule was excised by conjunctival scissors to the level of the mark. The roughened surface of the limbus was smoothened with surgical blade and haemostasis was maintained by pressing with wet gauze for 2-3 minutes. Covering the recipient bed by piece of wet gauze the globe was rotated inferomedially to expose the superotemporal donor site. The size of the graft was dependent on the circumferential and radial size of scleral part of pterygium. On both the circumferential and radial size of the graft we added $1 \mathrm{~mm}$ from the excised amount to allow for retraction. The conjunctiva was dissected free of tendon's capsule and sutured on the recipient site with 68 interrupted $8 / 0$ or $9 / 0$ virgin silk. Thirty one of the operations were done under OPMI and the other three cases were done with Zeis magnifying loop of $2.3 \mathrm{x}$ magnification. One surgeon during the third and fourth year residency programme did all the operations. After operation tubicort eye suspension was instilled and gentamicin $20 \mathrm{mg}$ subconjunctivally was given for each case and the eye was patched for 24 hours.

All patients were operated on as outpatients. There was no restriction in patient activity. Post-operative evaluation was done the next morning for remnants, position of flap, retroflap haemorrhage and visual acuity. Then patients were followed at one week, two months, six months and one year. If the need arose due to complications, patients were followed as required. Post-operatively patients were treated with chloramphenicol eyedrops four times daily tubicort eye suspension two times daily for six to eight weeks. In the first 10 days, all patients were given dexamethasone $0.1 \%$ eyedrops four times daily.

Finally, recurrence rates between different procedures were compared using two proportions for calculating statistical significance.

\section{RESULTS}

There were 55 patients with grades III and IV pterygia diagnosed clinically. Thirty two primary and two secondary pterygia patients agreed to undergo pterygium excision with free conjunctival autograft and the other 21 patients refused the procedure.

The duration of pterygia by history before operation was 1 - 5 years in twenty, 6 - 10 years in nine, and greater than 10 years in five. The main complaints of the patients were visual in 18 , irritation (itching, tearing, photophobia and foreign body sensation) in 14 and cosmetic in two patients. All pterygia were located nasally, fourteen being in the right eye and twenty in the left eye. According to the size of pterygium, 21 of the primary and one of the secondary pterygia were grade III and the others were grade IV (11 primary and one secondary). When we saw the natures of pterygial tissue, two secondary and six of the primary pterygia were inflamed, 24 of the primary pterygia were quiet and another two patients had primary atrophic pterygia. The diagnosis of pterygia in 21 patients was confined by histopathologic analysis.

Out of the 34 patients who were operated upon, 20 were males and 14 were females with a male to female ratio of 1.4:1. The age of these patients ranged from 28 to 72 years with a mean age of 46 years. The highest prevalence, $21(61.76 \%)$, of the cases was found in the age group between 41 and 50 years. This was followed by five patients $(14.70 \%)$ of the in the age group of $31-40$ years (Table 1). 
Table 1

Sex and age distribution of pterygia patients

\begin{tabular}{|c|c|c|c|}
\hline \multirow[t]{2}{*}{ Age group } & \multicolumn{2}{|c|}{ Sex } & \multirow[t]{2}{*}{ Total $(\%)$} \\
\hline & Male & Female & \\
\hline $20-30$ & 2 & 1 & $3(8.8)$ \\
\hline $31-40$ & 3 & 2 & $5(14.70)$ \\
\hline $41-50$ & 11 & 10 & $21(61.76)$ \\
\hline $51-60$ & 3 & 0 & $3(8.8)$ \\
\hline$>60$ & 1 & 1 & $2(5.9)$ \\
\hline Total & 20 & 14 & $34(100)$ \\
\hline
\end{tabular}

Table 2

Distribution of patients by occupation

\begin{tabular}{lc}
\hline Profession & No. of patients $(\%)$ \\
\hline Farmer & $8(23.5)$ \\
House-wife & $5(14.7)$ \\
Merchant & $6(17.6)$ \\
Soldier & $4(11.7)$ \\
Office worker & $3(8.8)$ \\
Driver & $1(2.9)$ \\
Carpenter & $1(2.9)$ \\
Laboratory technician & $1(2.9)$ \\
Physician & $1(2.9)$ \\
Factory worker (tobacco factory) & $3(8.8)$ \\
Guard & $1(2.9)$ \\
\hline Total & $34(100)$ \\
\hline
\end{tabular}

The highest proportions of patients were farmers by occupation, which was followed by soldiers, merchants and housewives (Table 2). The duration of post-operative follow up was six to nine months in 18, 10 - 12 months in five and greater than one year in nine patients. Two patients were lost to follow up after three months and there were no signs of recurrence on the last examination. There were two patients with recurrent pterygia. Recurrence was detected between three and four months post-operatively in both cases.

When we consider the two patients lost to follow up as having no recurrence, the rate of recurrence pterygia was $5.88 \%$. The visual acuity of all patients with no recurrence was assessed in the pre-operative and post-operative days as well as in the last visits with Snellen's acuity chart. The visual acuity remained the same in eight patients and improved in 24 cases. There were no intra-operative complications in all patients. In the last assessment eight of the patients had clean cornea. Twenty one had nebula cornea, and three had macula cornea and in the other two there were quiet fibrovascular growth which crossed the limbus (1.5 and $2 \mathrm{~mm}$ ). Except five patients who were complaining of itching and photophobia all the other patients with no recurrence were highly satisfied.

\section{DISCUSSION}

The predominance of males over females in our study is in agreement with other reports $(7,18)$. The reason suggested for the higher prevalence of pterygium in males was that males have higher exposure rates to environmental factors than females because of work-related conditions(9). Pterygium occurs twice as often in men as in women, and is more common in farmers than in city dwellers and also in people who do not wear spectacles, compared with those who $\operatorname{do}(7,18)$.

The highest prevalence of $61.76 \%$ was found in the age group between 41 and 50 years. This was followed by $14.70 \%$ in patients aged between 31 and 40 years. This finding was in agreement with the reports of Karukonda $e t$ al(7). It was previously noted that the peak incidence of pterygium occurs between the age of 20 and 40 years while the elderly have a higher prevalence. However, a recent study from Hong Kong, a location $22^{\circ}$ away from the equator, showed a peak incidence between the age of 50 and 80 years. It may be that the biosynthetic processes responsible for pterygium take place at a more rapid rate near the equator, when we compare with location such as Hong Kong, which is further from the equator. Since Ethiopia stretches from $3^{\circ}$ to $18^{\circ}$ north of the equator, the high prevalence of pterygium in the younger age groups was in accordance with other reports.

It has been accepted for some time that environmental factors are responsible for the development of pterygium(2,9). More recently, it has become clear that ultraviolet light (UVL) exposure is the most important environmental influence and that high exposure in the second and/or third decade of life is particularly relevant to causation $(9,18,19)$. In the examination of more than 100,000 Aborigines and non-Aborigines in rural Australia a strong positive correlation between climatic UV radiation and prevalence of pterygium was found(18).

Out of the 34 pterygia patients treated with free conjunctival autograft, there were two $(5.88 \%)$ recurrent pterygia. When we compared our results with bare scleral technique done in the same setting by Ayehuberhan(21) and reports of Kirkness et al(4), the recurrence rate in our series was significantly low (CI between $0.37,0.73$ and 0.40. 0.72 respectively). Our recurrence rate was not significantly different from other conjunctival autograft reports $(\mathrm{p}=0.41, \mathrm{CI}-0.12$. 0.26) $(3,4,12,15)$. Both patients with recurrent pterygia were treated for quiet, primary grade III pterygia. In both patients recurrence was detected between the second and fourth months post-operatively. They were a textile factory worker and a farmer.

In a retrospective analysis of pterygia cases operated at Menelik II tertiary Hospital Ophthalmology Department from September 1982 through August 1989 by bare scleral technique, $61.1 \%$ recurrence rate was reported(21). Recurrence of pterygium commonly occurs within six months after surgery(16). In a study, which was done by Asergadoo(17), if pterygium is going to recur, it usually grows back or shows signs of doing so during the first three months. Recurrence is sometimes seen as late as nine months. In a recent study to define the time interval necessary to follow patients after pterygium removal to identify a recurrence a one - year follow up time was likely to identify a recurrence(20). 
The effect of surgery on visual acuities of eyes not developing a recurrence was quite rewarding. In 24 (75\%) of the patients the visual acuity improved by one or more lines and in eight $(25 \%)$ of the patients the visual acuity remained the same. In a similar study, visual acuity was improved by two or more lines in 54\% of patients(4). The high rate of visual improvement in our patients may be because of inclusion of improvement by one line on the Snellen's chart.

This prospective study has demonstrated that conjunctival autografting is a safe surgical technique for reducing the probability of recurrences of pterygium after surgery. It can be recommended for the management of both primary and recurrent pterygia and is as effective as and safer than surgery combined with beta-irradiation or mitomycin drops. Therefore, it is recommended that a larger prospective study should be done to include people in different geographic locations.

\section{ACKNOWLEDGEMENTS}

I am grateful to Dr Wound Alemayehu instructor at Addis Ababa University Ophthalmology Department who reviewed the manuscript and Mr Zewdu Teshome for secretarial services.

\section{REFERENCES}

1. Kaniski J. J. Clinical Ophthalmology. Third ed. Pterygium. Butterworth-Heinemann Ltd Publisher, 96, 1994.

2. Duke-Elders. Systems of Ophthalmology. 5th .ed.Vol. VII. Part I. Diseases of the outer eye. Conjunctival diseases: degenerative and pigmentary changes. London. Henry Kipton publisher. 568, 1977.

3. McDonnel, P.J., Labrec, L.D, Kazav, Arvasu, R.G and Chen, P.P. Randomized trial comparing mitomycin 'c' and conjunctival autograft after excision of primary pterygium.Amer. J. Ophthalmol. 1995; 120:151-159.

4. Kirkness, C.H., Steele, A.D., M.C.G., Fickerl, A., Kielhorn. L.and Roirdan, E.V.A. P. Conjunctival autografting in the surgical management of pterygium. Eye. 1993; 7:634-638.

5. Pinkerton, O.D., Hokman, Y. and Shigemura, LA. Immunologic basis for the pathogenesis of pterygium. Amer. J. Ophthalmol. 1984; 98: 2256.
6. Costed, D. Pterygium: An ophthalmic enigma.Brit. J. Ophthalmol. 1995; 74:304-305.

7. Karukonda. S.R.K., Thomson, H.W., Beuerman, R.W., Law, D.S.K., Wilson, R, Chew, S.J. and Steinman, T.L. Cell cycle kinetics in pterygium at three latitudes. Brit. J. Ophthalmol. 1995; 79:313-317.

8. Hagon and Zimmerman. Ophthalmic pathology ed. II. Conjunctival degenerations. Copy right by W.B. Saunders Company. 252, 1962.

9. Darrel, R.W. and Bachrach, C.A. Pterygium among Veterans: An epidemiological study showing pterygium and degree of exposure to Uv in sunlight, Arch. Ophthalmol. 1993; 70:158-169.

10. Tseng, S.C.G. Staging of conjunctival squamous metaplasia by impression cytology. Ophthalmology. 1985; 92:728-733.

11. Aratoon, V. Surgery of pterygium by conjunctival pedicle flap. Amer. J. Ophthamol. 1967; 63:1778-1779.

12. Kenyon, K.R., Wagner, M.D. and Hettinger, M.E. Conjunctival autograft transplantation for advanced and recurrent pterygium. Ophthalmology. 1985; 92:1461-1470.

13. Hayasaka, S.. Noda Sachikd, Yomamato; Y. and Setegawa, T. Postoperative instillation of low dose mitomycin $\mathrm{C}$ in the treatment of Primary Pterygium. Amer. J. Ophthalmol. 1988; 106:715-718.

14. Youngson, R.M. Recurrence of pterygium after excision. Brit. J. Ophthalmol. 1972; 56:120-125.

15. Lewallen, S. A randomised trial of conjunctival autografting for pterygium in the tropics - Ophthalmology. 1989; 96:1612-1614.

16. Hayasaka, S., Noda, S., Yamarnotoy, Setogawa, T. Postoperative instillation of mytomycin $\mathrm{C}$ in the treatment of recurrent pterygium. Ophthal. Surg. 1989; 20:580-582.

17. Asregadoo, E.R., MD. Surgery. Thio-TEPA and corticosteroid in the treatment of pterygium. Amer. J. Ophthalmol. 1972; 74:960.

18. Moran, D.J. and Hollows, F.C. Pterygium and Ultraviolet light radiation. A positive correlation. Brit. J. Ophthalmol. 1984; 68:343-346.

19. Mackenzie, F.D., Hrst, L.W., Battistutta, D. and Green, A. Risk analysis in the development of ptreygia. Ophthalmology. 1992; 99:1056-1061.

20. Hirst, L.W., Sebban, A. and Chant, D. Pterygium recurrence time. Ophthalmology. 1994; 101:755-758.

21. Ayehu Berhan, G. A retrospective analysis of recurrence rates of pterygium following bare scleral technique in Menelik II Hospital, Department of Ophthalmology, Addis Ababa University, unpublished report 1989. 